\title{
THE USE OF GEOMAGNETIC FIELD MODELS IN MAGNETIC SURVEYS
}

\author{
R. D. REGAN \\ J. C. CAIN \\ (NASA-TM-X-70777) THE USE OF GEOMAGNETIC \\ N 75-11547 \\ FIELD MODELS IN MAGNETIC SURVEYS (NASA) \\ 21 P HC $\$ 3.25$ \\ CSCI $\quad 08 \mathrm{~N}$ \\ Unclas \\ $63 / 40,02764$ \\ SEPTEMBER 1974
}

\section{GLOBAL GEOMAGNETISM PROJECT}

GODDARD SPACE FLIGHT CENTER

Greenbelt, Maryland

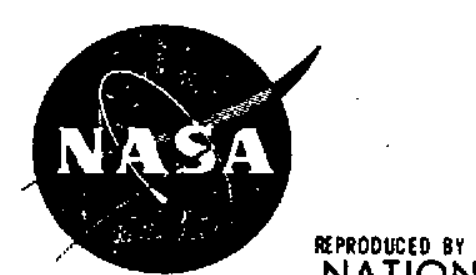

NATIONAL TECHNICAL

INFORMATION SERVICE

U.S. DEPARIMENI OF COMMERCE
U. S. GEOLOGICAL SURVEY Reston, Virginia

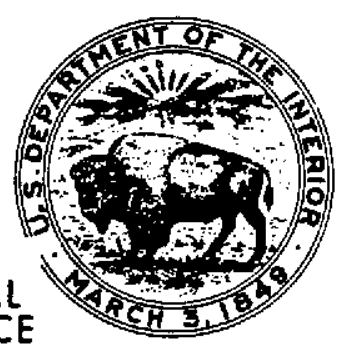

(S) 
"This paper presents the views of the author(s), and does not necessarily reflect the views of the Goddard Space Flight Center, or NASA."

For information concerning availability of this document contact:

Technical Information Division, Code 250 Goddard Space Flight Center

Greenbelt, Marylend 2077!

(Telephone 301-982-4488) 
$X-922-74-295$

PREPRINT

THE USE OF GEOMAGNETIC FIELD MODELS

IN MAGNETIC SURVEYS

R. D. Regan

J. C. Cain

September 1974

GLOBAL GEOMAGNETISM PROJECT

GODDARD SPACE FLIGHT CENTER

Greenbelt, Maryland 


\title{
THE USE OF GEOMAGNETIC FIELD MODELS \\ IN MAGNETIC SURVEYS*
}

\author{
Robert D. Regan** \\ Joseph C. Cain***
}

\begin{abstract}
Global geomagnetic field models, usually computed from spherical harmonic series, are becoming of increased importance in the reduction of magnetic surveys. When used correctly, a numerical model of sufficient complexity, including adequate secular variation correction, provides a suitable representation of the regional field. The best known and mostly widely used of the available field models is the International Geomagnetic Reference Field (IGRF). However, the IGRF may not be suitable for the reduction of all magnetic survey data because of its imperfect fit to the main field, particularly for years since 1968 .
\end{abstract}

\section{PABCEDING}

"Submitted to "Geophysics" September 1974

**U.S. Geological Survey

***NASA/Goddard Space Flight Center, Greenbelt, Md.

\section{Preceding page blank}


CONTENTS

$\underline{\text { Page }}$

ABSTRACT . . . . . . . . . . . . . . . . . ili

INTRODUCTION . . . . . . . . . . . . . . . . . 1

FIELD MODELS . . . . . . . . . . . . . . . . 2

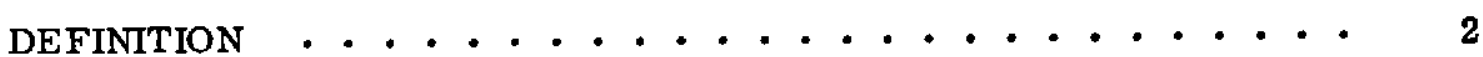

PRACTICAL CONSIDERATIONS . . . . . . . . . . . . 3

Data Distribution . . . . . . . . . . . . . 3

Secular Variation ..................... 3

Maximum Degree ... . . . . . . . . . . . . 4

VARIOUS FIELD MODELS . . . . . . . . . . . . . 5

FIELD MODELS IN MAGNETIC SURVEYS $\cdot$ • • • • • • • • 5

USE OF THE IGRF . . . . . . . . . . . . . . . . 6

IMPERFECT FIT . . . . . . . . . . . . . . 7

SECULAR VARIATION ERROR . . . . . . . . . . . • 8

IMPROPER USE ..................... 10

CORRECTIONS TO THE IGRF . . . . . . . . . . . . . 10

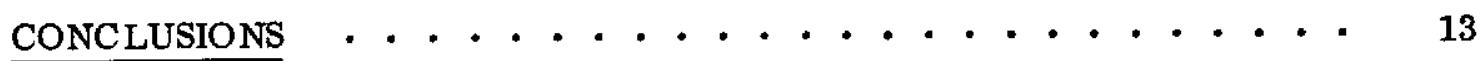

REFERENCES ...................... . . 14

PRBCEDING PAGE BLANK NOT FILNED

Preceding page blank 


\section{ILLUSTRATIONS}

Figure

Page

1 Total intensity magnetic data from segment of Glomar Challenger leg 24. Solid line is measured data; dashed line is magnetic field calculated with POGO $(8 / 71)$ field model.

2 Difference in total field between the POGO $(8 / 71)$ and IGRF field models. Date $=1966.0$, altitude $=0.0 \mathrm{~km}$, contour interval 25 gammas.

3 Difference in total field between the POGO $(8 / 71)$ field model truncated at order and degree eight and the IGRF field model. Date $=1970.0$, altitude $=0.0 \mathrm{~km}$, contour interval is 25 gammas.

4 Total magnetic field over state of Indiana calculated from GSFC $(12 / 66)$ model. Date $=1947.0$, altitude $=1700 \mathrm{feet}$, contour interval is 75 gammas. . . . . . . . . . . 11

5 Difference in total field, over state of Indiana, between GSFC $(12 / 66)$ field model, date $=1947.0$ and IGRF field model, date $=1966.0$. Altitude $=1700$ feet, contour interval is 5 gammas. $\quad 12$

6 Proposed correction for IGRF secular terms, see text for further discussion.

TABLES

Tâble

1 Characteristics of Several Geomagnetic Field Models

Page 


\section{THE USE OF GEOMAGNETIC FIELD MODELS IN MAGNETIC SURVEYS}

\section{INTRODUCTION}

The primary goal in the reduction of magnetic survey data is the accurate determination of the residual (or anomalous) magnetic field associated with the geological structures being investigated. This residual field has a different meaning (and structure) depending upon the goals of the survey. Usually local surveys are topical, seeking the anomalous magnetic field associated with fairly isolated, restricted sources, whereas broad-scale more territorial surveys are concerned with the magnetic structure of a significant part of the crust. In either case, the main geomagnetic field arising from the earth's core (the inducing or primary field), and, for the smaller scale surveys, some part of the induced (or secondary) field, must be removed from the survey data. These components of the observed field are usually termed the regional field. There have been many philosophical discussions on the nature of this field separation (e.g. , Grant, 1954, 1957; Vajk, 1954), and several techniques for the separation are routinely used (e.g., various graphical methods, Nettleton, 1954; Polynomials, Oldham and Sutherland, 1955; Continuation, Peters, 1949, Henderson and Zietz, 1949).

An alternative method is the use of a geomagnetic field model to define the regional magnetic field. This method takes on increased importance in the datareduction procedure, as magnetic surveys cover continually increasing areas and as adjacent surveys are separated by substantial time intervals. When the regional field is determined by a technique such as polynomial fitting, a new polynomial fit must be redetermined whenever the survey area is increased or whenever contiguous surveys are compiled to form a regional map. Furthermore, sharp discontinuities can occur when adjoining surveys, separated by a significant time interval, for example, 10 to 20 years are compiled. These problems become more tractable when a geomagnetic field model is used to define the regional field.

We have already reached the point where surveys are being compiled into smallscale regional maps and where there is a significant time difference between adjacent surveys. Examination of the U.S. Geological Survey aeromagnetic mapping program (Kane, 1973) reveals areas where adjoining Statewide surveys are separated by as much as 20 years; for example, Michigan was surveyed in 1969 , and the aeromagnetic survey of Indiana was flown in 1947. Maps representing the anomalous magnetic field over many States, have been compiled from individual surveys (Zietz and Zen, 1973).

A suitable choice for determining the regional field in these surveys, and in magnetic surveys in general, is a global geomagnetic field model. This paper details the concept of geomagnetic field models and their use in magnetic surveys and discusses the limitations of those models presently available, particularly the International Geomagnetic Reference Field (IGRF). 


\section{FIELD MODELS}

\section{DEFINITION}

Basically, a geomagnetic field model (or field model) is a four-dimensional function representing the main geomagnetic field at any point in space and time. It is a function of latitude $(\phi)$, longitude $(\theta)$, altitude (or geocentric distance) (r), and time $(\mathfrak{t})$.

Using the spherical harmonic series representing the scalar potential of the field

$$
V=a \sum_{n=1}^{\infty}\left(\frac{a}{r}\right)^{n+1} \sum_{m=0}^{n}\left(g_{n}^{m} \operatorname{cosm} \phi+h_{n}^{m} \sin m \phi\right) P_{n}^{m}(\theta)
$$

where:

$$
\begin{array}{ll}
\mathrm{V} & =\text { magnetic scalar potential } \\
\mathrm{a} & =\text { mean radius of the earth } \\
\mathrm{m}, \mathbf{n} & =\text { order, degree } \\
\mathrm{P}_{\mathbf{n}}^{\mathrm{m}}(\theta) & =\text { Schmidt's quasinormalized spherical functions }
\end{array}
$$

The set of Gauss coefficients $g_{n}^{m}, h_{n}^{m}$ are determined by a least-squares fit to a global distribution of data (Cain et al., 1967). This set of data may be composed of surface, aircraft, and satellite magnetic measurements obtained at various times. Such a potential is only strictly applicable in interpolating (or extrapolating) magnetic field observations in a region free of current sources. Indications are that such an assumption is quite valid to an accuracy of better than 10 gammas, excluding polar regions.

A time parameter may be introduced into the model by expanding the Gauss coefficients in a finite Taylor series about some mean time of the data set $\left(t_{0}\right)$,
termed the epoch,

and

$$
g=g_{0}+g^{\prime}\left(t-t_{0}\right)+\frac{g^{\prime \prime}}{2}\left(t-t_{0}\right)^{2}+\ldots
$$

$$
h=h_{0}+h^{\prime}\left(t-t_{0}\right)+\frac{h^{\prime \prime}}{2}\left(t-t_{0}\right)^{2}+\ldots
$$

Thus the least-squares fit is usually made in four dimensions. The complete set of coefficients consists of the Gauss coefficients $(g, h)$ and at least the first-order secular change coefficients $\left(\mathrm{g}^{\prime}, \mathrm{h}^{\prime}\right)$. Some models are made with a separate determination of secular change, using only repeat station or observatory data (e.g. , Hurwitz et al., 1974). 
The various published field models for example, Leaton et al., 1965; Cain et al. , 1967; Cain and Cain, 1971; consist of these coefficients in tabular form. These are then used in the appropriate form of the spherical harmonic series to calculate either component or total field values at any point in space and time.

\section{PRACTICAL CONSIDERATIONS}

In the calculation of field models, consideration must be given to the practical restrictions of the nonuniform distribution of the data, secular variation, and maximum degree of the fleld model, all of which ultimately influence the utility of the model.

\section{Data Distribution}

Charts of land, sea, and airborne magnetic survey coverage during this century (Fabiano and Cain, 1971) reveal sizable areas containing few or no measured values. Although in the past decade, satellites have aided considerably in providing global coverage, at present their measurements are only of the total field. Models based only on these measurements are very precise in representing total field values at satellite altitudes but may be deficient in determining accurate vector values (Stern and Bredekamp, 1974).

The irregular distribution of data prohibits the accurate definition of the higher order components and can cause an aliasing effect in the lower order terms. The aliasing effect can be minimized by carrying the analysis to such a high degree, within the limitations of the data distribution, that the neglected high-order harmonics contain little power (Cain et al., 1967). Another method to minimize the effects of the irregular data distribution is to construct an equal-area grid over the measured values. By determining representative values from the raw data in each grid segment, a more uniform distribution is available for model computation (Cain et al., 1967).

\section{Secular Variation}

To obtain a sufficient amount of data with reasonable distribution, measurements obtained over a time span of a decade or more must be utilized. During this interval, the main field values would have varied in a nonuniform and unpredictable manner. Either the measurements must be "corrected" for this temporal or secular variation, or the changes must be incorporated into the models. As previously mentioned, this may be accomplished for intervals of as much as about 20 years by expanding the Gauss coefficients in a finite Taylor series about some mean time in the data set and simultaneously solving for the time derivatives 
(termed secular change coefficients). For very long time intervals it would be more appropriate to expand the coefficients into periodic functions (Braginsky, 1972).

These methods help interpolate over the time span of the raw data, and use of the coefficients permits the calculation of the main field values at any point in time. Additional information such as observatory annual means are usually included in the raw data to aid in the determination of the secular variation and to check the results. Again, however, this technique results in some errors because of having a non-uniform data set over the parameter space.

Maximum Degree

An important parameter in the calculation of the field model is the maximum degree (or $\mathrm{n}^{*}$ ). Each value of $\mathrm{n}$ in the spherical harmonic expansion is a global wavenumber; that is, each harmonic represents variations of the potential whose wavelengths are approximately $40,000 / \mathrm{n}$ kilometers. This is not strictly true for the variations of the total field, for as has been pointed out by Benkova et al. (1973), the total field variations are not exactly identical with those of the potentail but may be "smeared" by several degrees (n). Still, the complexity of a field model is determined by its maximum degree, so that a high $n^{*}$ permits modeling smaller wavelength components of the field. However, the number of coefficients increases rapidly with degree. A field model of maximum degree $\mathrm{n}$ is composed of $(n+1)^{2}-1$ Gauss coefficients and at most an equal number of first-and secondorder secular change coefficients. Thus, as $n *$ increases, the number of calculations and the amount of associated computer time and storage used in the leastsquares analysis increases rapidly, approximately as $\left(n^{*}\right)^{4}$.

Usually the series is truncated at a harmonic degree at which the root mean square of the fit does not decrease significantly upon computing higher degree coefficients or at some prior arbitrary point necessitated by computer limitations.

In the most recent satellite models, the root mean square of the fit docs not decrease by more than 1 gamma $\dagger$ as $n^{*}$ increases from 11 to 13 . Typically, at satellite altitudes these high-order models have a goodness-of-fit to the data of 4 gammas, whereas models based on ground data have about 150 gammas. This high figure for the surface level is mainly due to the distribution of surfaceanomaly noise in the data.

tgamma is used to denote $10^{-9}$ Tesla 
For ideal modeling of the main geomagnetic field, the maximum degree of the model should correspond to that point in the power spectrum where the power of the main (core) field has decreased to zero. However, to date there has not been agreement on the form of the spectrum. Alldredge et al., (1966) and Bullard (1967) argued for $\mathrm{n}^{*} \mathrm{~s}$ of 11 and 25 respectively, based on spectral analyses. However, even when such a point is established, some of the terms associated with the core field would also contain contributions from the induced magnetization of the crust.

\section{VARIOUS FIELD MODELS}

The field model most often used is the International Geomagnetic Reference Field (IGRF). This model, a composite of several models, was derived by computing weighted averages of coefficients of proposed models at the IAGA symposium in Washington, D. C., in 1968 (Zmuda, 1971). Cain and Cain (1971) presented a detailed discussion of the derivation of this model and its comparison with the proposed models.

In addition to the IGRF, many other field models, with various parameters, are available for use. The characteristics of several of these models are listed in Table 1. Because the IGRF is a composite of several models, it is difficult to assign a meaningful data interval to it. However, no data later than 1966 were used in its derivation.

\section{FIELD MODELS IN MAGNETIC SURVEYS}

The use of field models can be an effective method to remove the background geomagnetic field from magnetic survey data. Because a field model is derived from global information, it more accurately represents the geomagnetic field than any function based solely on data from a particular magnetic survey. Ideally, for use in exploration geophysics, it would be desirable to have a field model to remove initially only that component of the main field which is due to the core (and possible the mantle). This would leave the geologically more interesting crustal signal which, depending on the objectives of the survey, could be further reduced, by other methods, to enhance the anomalous signal. However, at present, it is not clear how this core-crustal separation can be uniquely performed.

In surveys covering broad areas, a field model can be used to provide an effective regional residual separation. Although it is based on worldwide data, the field model does represent the regional field over the limited areas of a magnetic survey. The principal reason for this is that the magnetic signals of larger geological anomalies are contained in the data used to determine field models. One 
Table 1

Characteristics of Several Geomagnetic Field Models

\begin{tabular}{|c|c|c|c|c|c|}
\hline MODEL & EPOCH & $n$ & $\begin{array}{c}\text { SECULAR } \\
\text { TERMS }\end{array}$ & SOURCE DATA & $\begin{array}{c}\text { DATA } \\
\text { INTERVAL }\end{array}$ \\
\hline \hline GAUSS & 1835 & 4 & NO & GROUND & 1835 \\
\hline SCHMIOT & 1885 & 6 & NO & GROUND & $?$ \\
\hline VESTINE & 1946 & 6 & YES & GROUND & $?$ \\
\hline $\begin{array}{c}\text { FINCH AND } \\
\text { LEATON }\end{array}$ & 1955 & 6 & YES & GROUND & $?$ \\
\hline $\begin{array}{c}\text { GSFC } \\
\text { (I2/66) }\end{array}$ & 1965 & 11 & YES & $\begin{array}{c}\text { GROUND, AIRBORNE } \\
\text { AND SATELLITE }\end{array}$ & $1900-1965$ \\
\hline COSMOS-49 & 1964.8 & 5 & YES & SATELLITE & 1964.8 \\
\hline POGO (8/71) & 1970 & 13 & YES & GROUND AND SATELLITE & $1965-1970$ \\
\hline IGRF & 1965 & 8 & YES & $\begin{array}{c}\text { GROUNO, AIRBORNE } \\
\text { ANO SATELLITE }\end{array}$ & \\
\hline AWC(70) & 1970 & 12 & YES & GROUND AND AIRBORNE & $1939-1970$ \\
\hline
\end{tabular}

example of a regional signal calculated from a field model is illustrated in Figure 1. This is a 900-km segment on Glomar Challenger leg 24 provided by John Mudie, Scripps Institution of Oceanography (personal communication). In this figure, the field calculated from a thirteenth-order field model (POGO [8/71] , J. C. Cain, unpublished data) is shown with the measured data. Although no comparisons were made with other regional residual methods, the field-model results indicate a suitable regional field. Undoubtedly the utility of a field model as a regional residual technique depends on the scale of the survey. In a survey over a localized geological body, the regional field could be of too short a wavelength to be represented by a field model. However, the field model may still bo used in this case as a first step in the definition of the regional field.

\section{USE OF THE IGRF}

A magnetic anomaly (or residual) can be defined as the difference between the observed and computed (regional) magnetic field values. As with other techniques, inaccurate definitions of the anomalies can result when a field model is used to obtain the regional values. The limitations of the IGRF are detailed to illustrate this problem. The IGRF model was chosen because it has wide acceptance as a useful reference for magnetic survey reductions. 


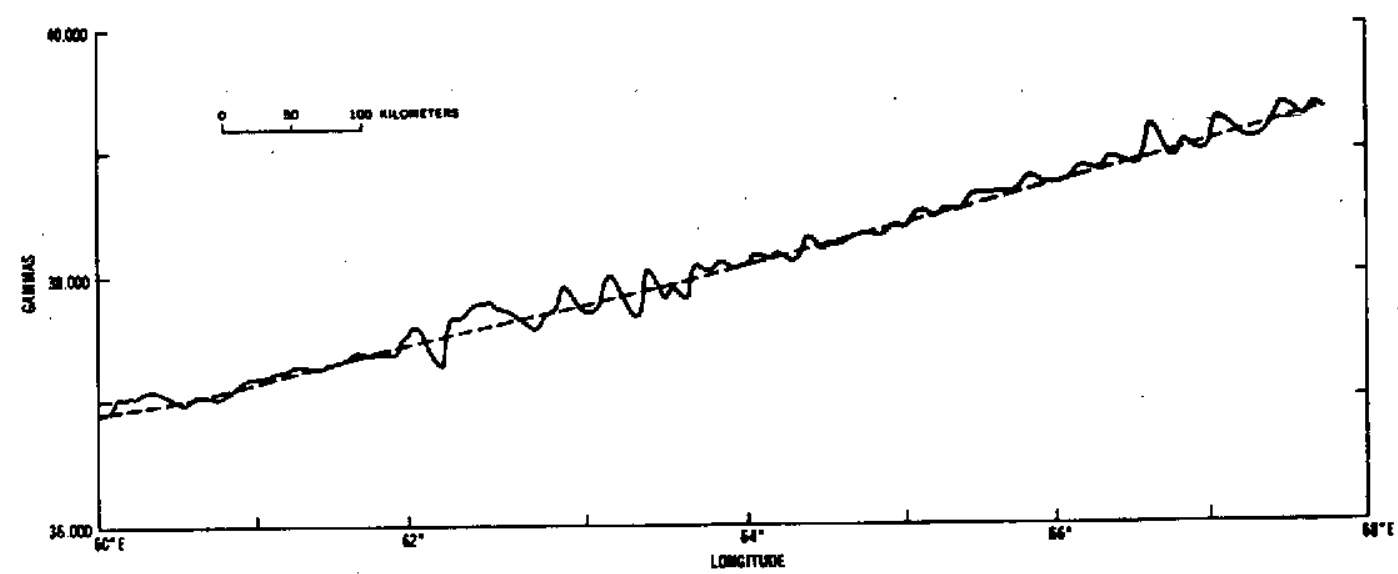

Figure 1. Total intensity magnetic data from segment of Glomar Challenger leg 24. Solid line is measured data; dashed line is magnetic field calculated with POGO $(8 / 71)$ field model.

The thirteenth-order POGO (8/71) field model is used as a basis of comparison to illustrate the limitations of the IGRF. Although this model probably has some errors in representing the vector components, its projection to the earth's surface is accurate in total field to better than 50 gammas over the POGO satellite (Cain and Langel, 1971) data interval of 1965.8 to 1970.3. It thus serves as a useful tool to explain the character of the systematic residuals from the IGRF that many users have encountered.

\section{IMPERFECT FIT}

Figure 2 shows the difference, at the earth's surface, in total field calculated with the POGO $(8 / 71)$ and the eighth-order IGRF field models. The differences were computed at an Epoch of 1965.0 to minimize differences resulting from secular change in the IGRF model. This was possible because it has been shown (Cain and Cain, 1971) that the IGRF is consistent with the early POGO data. Assuming the POGO $(8 / 71)$ field model to be representative of the actual geomagnetic field, this map demonstrates the residuals in the IGRF due to imperfect fit. This is not unique to the IGRF. Any model of maximum order eight would produce similar results. The variations are due solely to the fact that the shorter wavelength components of the main field are not being modeled.

These differences could be significant in the reduction of magnetic survey data if these shorter wavelength components are nongeologic in origin. Under this condition, this figure indicates the limitations in using an eighth-order model (and 


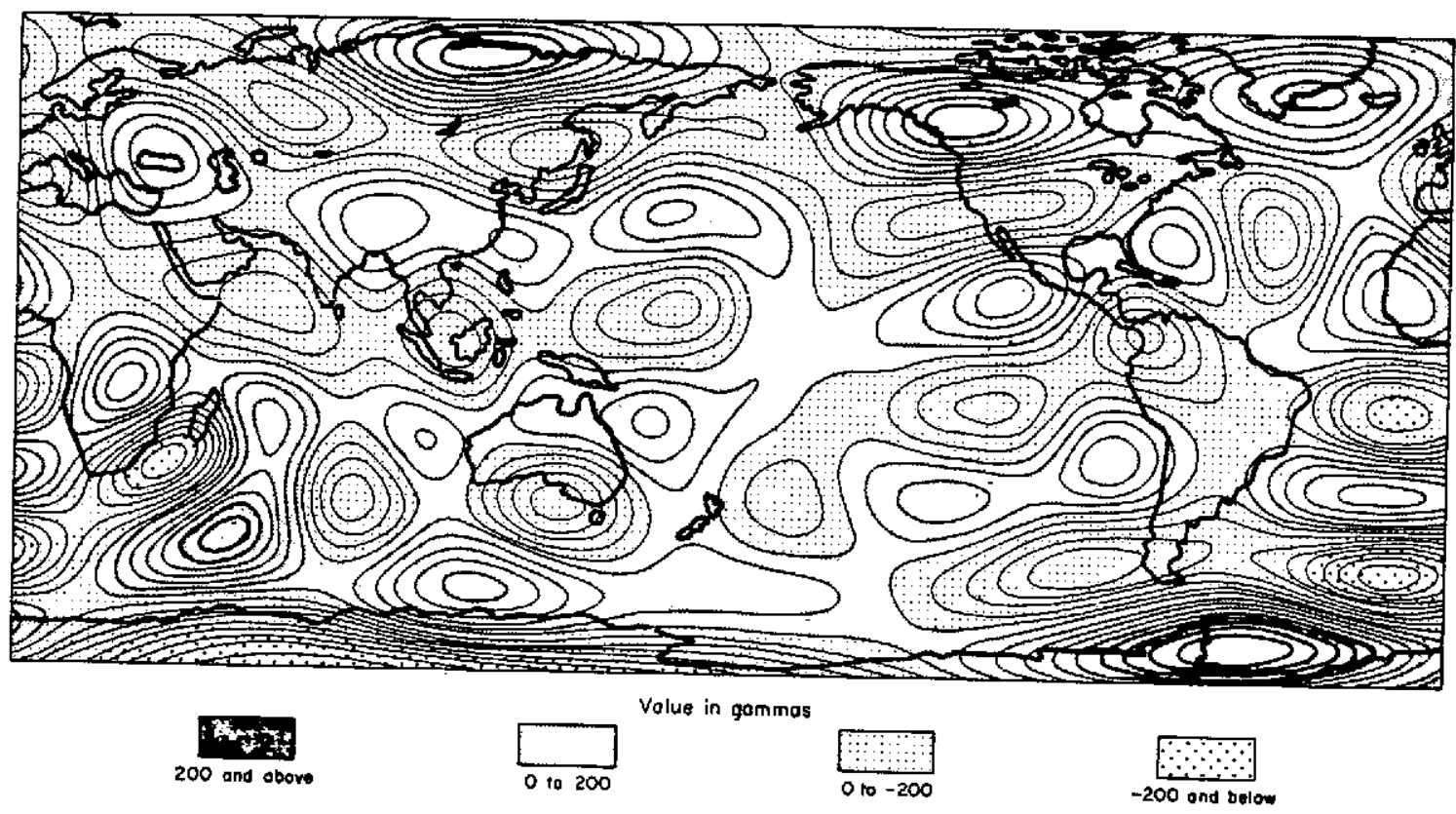

Figure 2. Difference in total field between the POGO $(8 / 71)$ and IGRF field models. Date $=1966.0$, altitude $=0.0 \mathrm{~km}$, contour interval 25 gammas.

the IGRF in particular) to reduce magnetic survey data. For example, if we consider the North American continent; no significant problems would be found in the reduction of data relating to areas the size of a State. However, structure could be introduced into the compilation of a map covering the entire continent or even a map of the United States or Canada.

Thus, there is a dependence between the area of the survey and the maximum order of the field model. Wavelengths less than approximately $40,000 / \mathrm{n} * \mathrm{~km}$ are not represented by a field model. Parts of this shorter wavelength structure that are of nongeologic origin would occur as false anomalies if the survey area is greater than their wavelength. Thus, higher order fields should be used if the magnetic survey covers a substantial area.

\section{SECULAR VARIATION ERROR}

The error introduced by the secular change extrapolation of the IGRF model is illustrated in Figure 3. This map shows the total fleld difference for 1970.0 at the earth's surface between the POGO (8/71) model, truncated at the elghth degree, and the IGRF model. The IGRF model has an epoch of 1965.0 , and a 


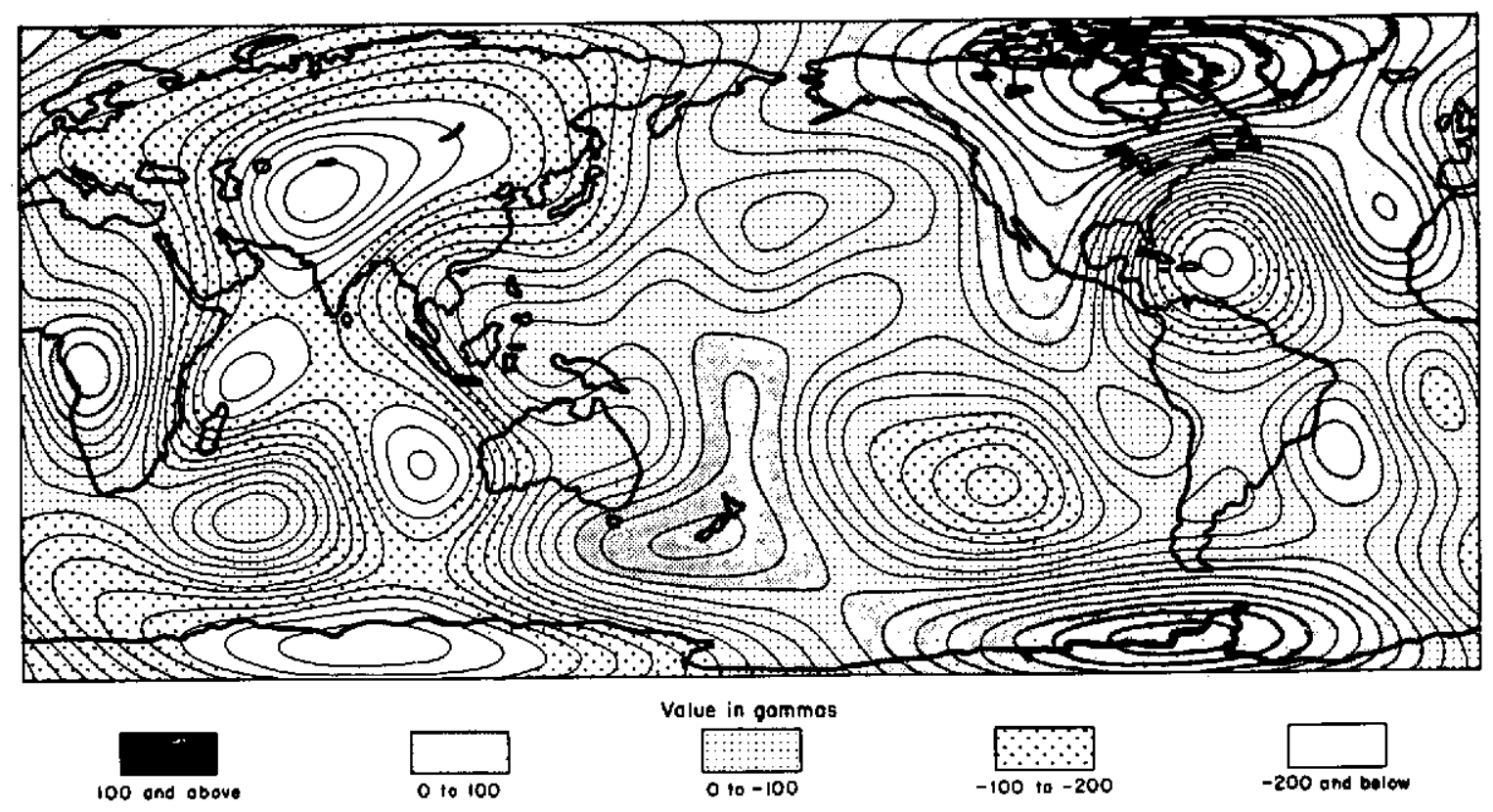

Figure 3. Difference in total field between the POGO $(8 / 71)$ field model truncated at order and degree eight and the IGRF field model. Date = 1970.0 , altitude $=0.0 \mathrm{~km}$, contour interval is 25 gammas.

secular change correction must be used to calculate the field at 1970. The POGO $(8 / 71)$ model contains $1970 \mathrm{data}$, and thus there is no extrapolation in time. The POGO $(8 / 71)$ field model was truncated at the eighth degree so as to detail the main features of the secular variation error without adding the effect of the errors due to truncation. An inspection of Figure 3 indicates large regions where the IGRF is departing from the true field as much as a few hundred gammas in 5 years. The large negative region over Asia and the Indian Ocean has been discussed by Cain and $J$ in (1973) as a result of significant changes in the secular variation patterns since 1965.

A comparison has also been made of the secular change of the higher order terms not represented on Figure 3 by evaluation of the changes in the POGO data. Although the projections to the surface of the higher order terms is more uncertain than that of the lower order terms, it appears that their secular variation over the 5-year period is less than a few tens of gammas, except in the vicinity of South America.

The IGRF secular change error (Figure 3) has a predominantly long wavelength structure and does not appear to have as serious an effect on data reduction as the error due to imperfect fit. The significance of an absolute error at any epoch 
is not too severe in the reduction of magnetic surveys so long as comparisons are not attempted with data reduced by the IGRF at other epochs. Residual maps for the United States using survey data from 1965 and 1970 would contain level changes on the order of 50 to 100 gammas, whereas those over other parts of the globe could be on the order of several hundred gammas. However, the total error in utilizing the IGRF model to reduce 1970 data would be a combination of that due to secuiar change and imperfect fit.

Unlike the error due to imperfect fit, the structure of this particular secular change error field is unique to the IGRF. Secular errors occurring in other field models could have a totally different structure.

\section{IMPROPER USE}

One error that can be easily avoided is that resulting from the improper use of a geomagnetic field model. An example is given to illustrate this error.

Figure 4 shows the geomagnetic field over Indiana in 1947, based upon the GSFC $(12 / 66)$ (Cain et al., 1967) model which contains 1947 data. Because data from the year 1947 was used in the derivation of this model, it would be a suitable choice to reduce the aeromagnetic survey data collected in that year. Figure 5 shows the total field difference at the survey altitude of 1700 feet between the field shown in Figure 4 and the IGRF field, calculated at its epoch of 1965.0. A similar result would occur by using the IGRF total field values (without the annual change correction) published by ESSA (Fabiano and Peddie, 1969). This publication shows the field calculated with IGRF at the earth's surface for 1965.0. The error would appear in the reduced survey data as a false residual gradient approximately $30^{\circ}$ to $40^{\circ}$ from the true field. Although this is only a hypothetical example, similar types of errors have occurred in the reduction of aeromagnetic
surveys.

\section{CORRECTIONS TO THE IGRF}

The IGRF model was selected to illustrate the sources of error because it is the best known and most frequently used fleld model. These examples point out the major limitations in the IGRF for use as a tool in magnetic survey reduction: (a) In most cases the calculated field differs from the measured field by a constant amount, and (b) the secular change correction is not accurate when extrapolated beyond 1968, a major limitation of the model.

The problem of the IGRF secular change correction was considered by the IGRF committee at the IAGA (International Association of Creomagnetism and Aeronomy) 


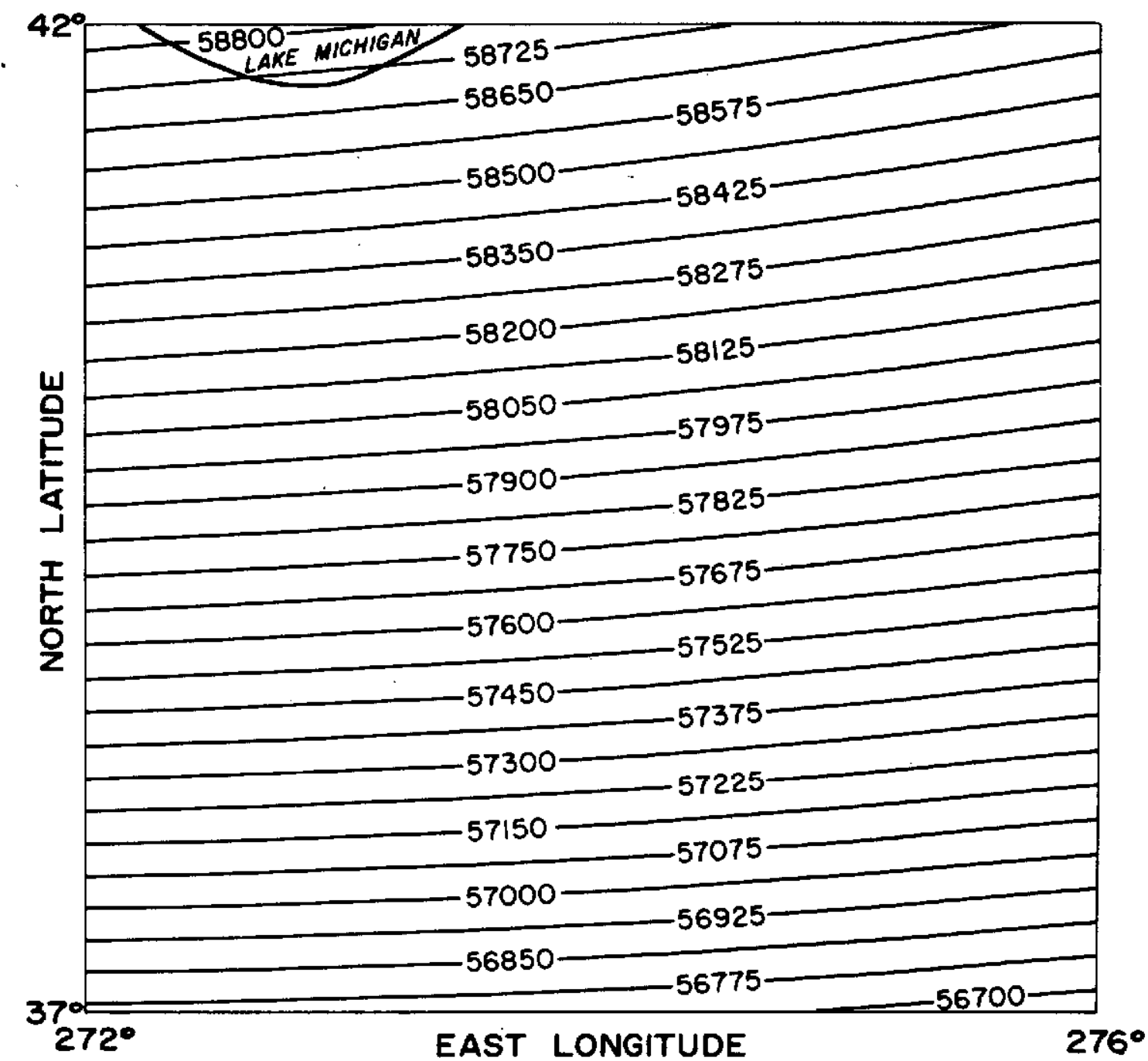

Figure 4. Total magnetic field over state of Indiana calculated from GSFC $(12 / 66)$ model. Date $=1947.0$, altitude $=1700$ feet, contour interval is 75 gammas.

meeting in Kyoto, Japan (Leaton, 1973). The committee's proposal was to correct the secular change coefficients in 1975 and to add a disclaimer to the model stating that it is not the most accurate model that could be produced but that it has merit as an international reference. The secular change error of the IGRF model and the correction suggested by the IGRF committee is shown conceptually in Figure 6. The solid line shows annual mean values calculated from geomagnetic observatory data to 1975. The dashed continuation of this line represents an extrapolation of these values to the years beyond 1975. The left part of the 


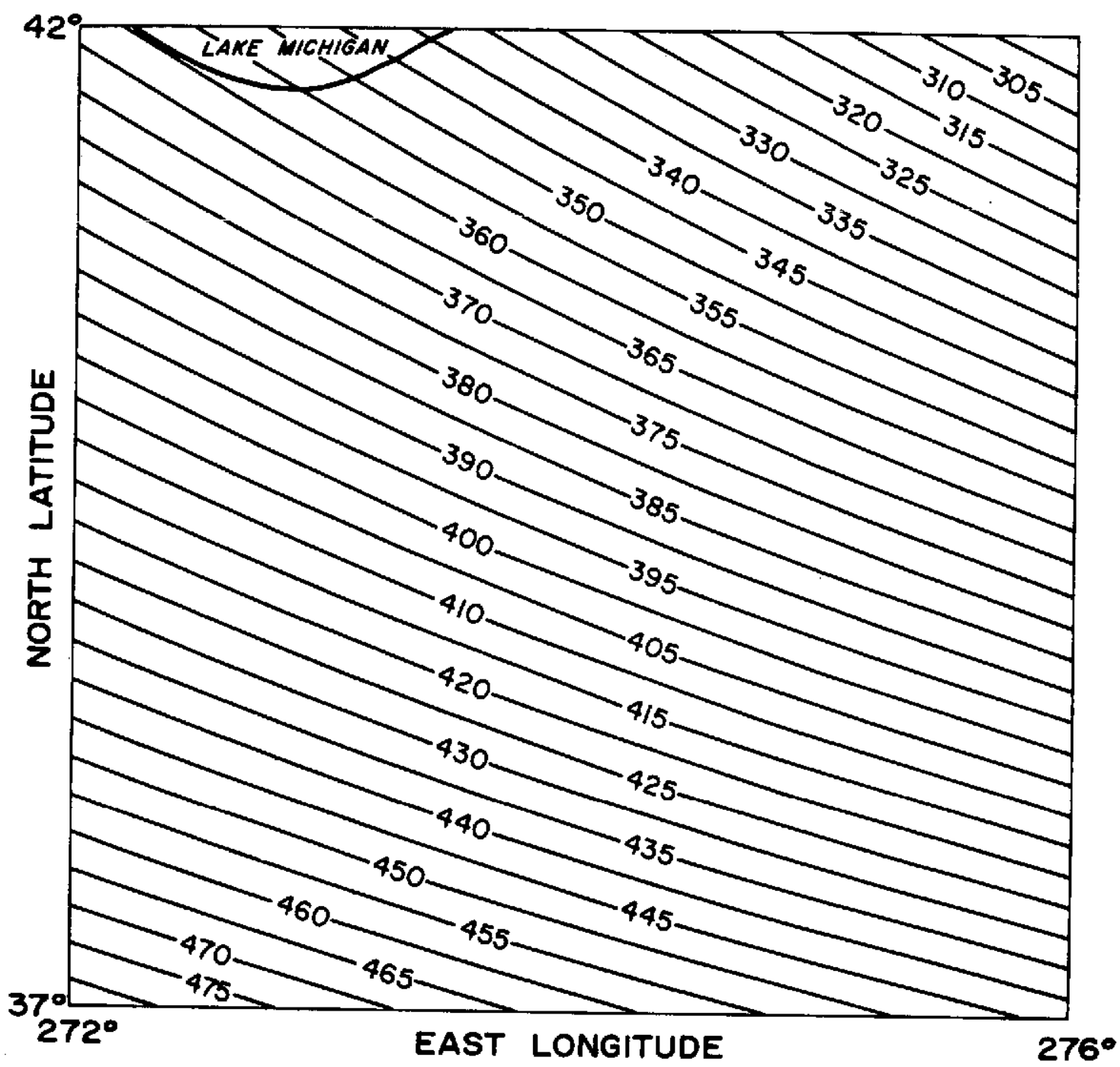

Figure 5. Difference in total field, over state of Indiana, between GSFC $(12 / 66)$ field model, date $=1947.0$ and IGRF field model, date $=1966.0$. Altitude $=1700$ feet, contour interval is 5 gammas.

lower line illustrates the annual means calculated with the IGRF model. The error in the secular change correction is readily apparent. The dotted line shows the effect of the proposed correction to the IGRF secular change coefficients. The calculated values would be off by a constant amount, and the calculated secular change would (hopefully) parallel the true secular change. The final decision on adoption of changes to the IGRF is to be made during the IUGG (International Union of Geodesy and Geophysics) Grenoble, France, in September 1975. 


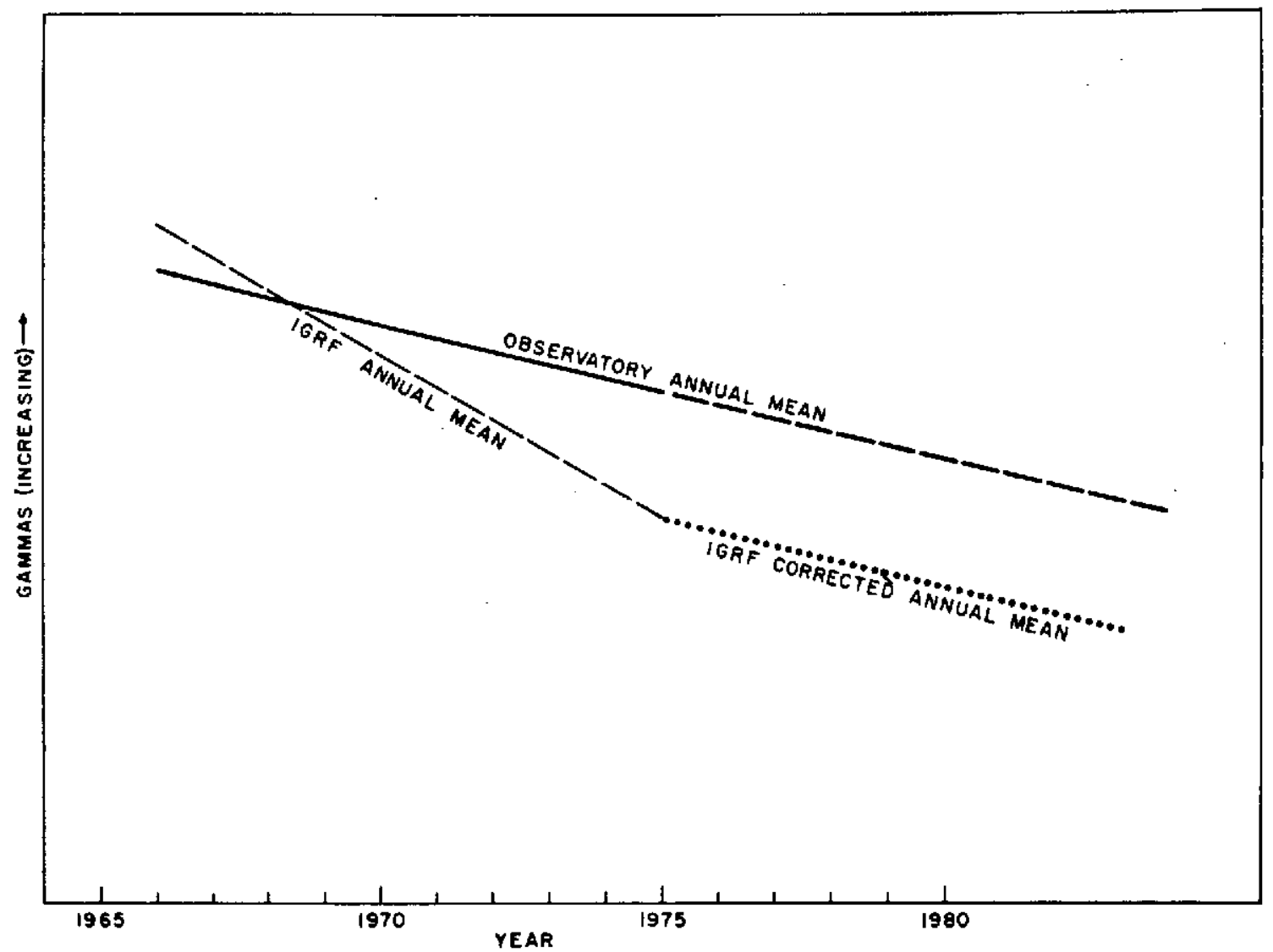

Figure 6. Proposed correction for IGRF secular terms, see text for further discussion.

\section{CONCLUSIONS}

When properly used, a geomagnetic field model of sufficient maximum degree and adequate secular variation correction provides a suitable regional magnetic field. However, the low harmonic degree and erroneous secular change correction of some models can introduce unwanted structure in the reduced survey data. These problems, as they apply to the IGRF, indicate that errors can occur when recent data or data of continental scale are reduced with this model. Although many alternative field models are available for use there is no internationally accepted field model particularly well suited for magnetic survey data reduction. Even with the proposed corrections, the IGRF is not the best model that could be developed for this purpose. 
An adequate field model for use in the reduction of magnetic survey data should be devised. The input data should have a time span that would cover the range of extensive magnetic surveys and as broad a scale of global coverage as possible. Now that the World Magnetic Survey has been completed (Zmuda, 1971), there are no firm plans to perform global surveys to monitor the secular change of the field. Hence, further adjustments to reference fisld models may need to be made on the basis of insufficient data.

The maximum degree of the model, perhaps the most crucial parameter, is yet to be determined. Continued research into the spectral structure of the field should aid in the definition of this parameter.

\section{RE FERENCES}

Allredge, L. R., Van Voorhis, G. D., and Davis, T. M., 1966, A magnetic profile around the world, Jour. Geophys. Research., vol. 68, No. 12, pp. 3679-3692.

Benkova, N. P., Dolginov, Sh. Sh., and Simonenko, T. N., 1973, Residual geomagnetic field from the satellite Cosmos 49 , Jour. Geophys. Research, vol. 78 , No. 5, pp. 798-803.

Braginsky, S. I., 1972, Spherical analyses of the main geomagnetic field in 1550-1800, Geomagnetism and Aeronomy, vol. 12, No. 3, pp. 464-468.

Bullard, E. C., 1967, The removal of trend from magnetic surveys, Earth and Planetary Sc1., Letters, vol. 2, pp. 293-300.

Cain, J. C., 1971, Geomagnetic models from satellite surveys, Rev. Geophysics and Space Physics, 9, pp. 259-273.

Cain, J. C., and Cain, S. J., 1971, Derivation of the International Geomagnetic Reference Field [IGRF (10/68)], U.S. Natl. Aeronautics and Space Admin., NASA Tech. Note D-6237.

Cain, J. C., Daniels, W. E., and Hendricks, S. J., 1965, An evaluation of the main geomagnetic field, 1940-1962, Jour. Geophys. Research, vol. 70, No. 15 , pp. 3647-3674.

Cain, J. C., Henricks, S. J., Langel, R. A., and Hudson, W. V., 1967, A proposed model for the International Geomagnetic Reference Field, Jour. Geomagnetism and Geoelectricity, vol, 19, pn. 335-355. 
Cain, J. C., and Langel, R. A., 1971, Geomagnetic survey by the polar orbiting geophysical observatories, in World Magnetic Survey, 1951-1969, Internat. Assoc. Geomagnetism and Aeronomy, Bull. No. 28, pp. 65-74.

Cain, J. C., and Jin, R. S., 1973, Geomagnetic secular change, Internat. Assoc. Geomagnetism and Aeronomy, Bull. No. 34, pp. 270.

Fabiano, E. B., and Cain, S. J., 1971, Coverage by land, sea, and airplane surveys, 1960-1967, in World Magnetic Survey, 1959-1969; Internat. Assoc. Geomagnetism and Aeronomy, Bull. No. 28, pp. 94-98.

Fabiano, E. B., and Peddie, N. W., 1969, Grid values of total magnetic intensity IGRF-1965, U. S. ESSA Tech. Rept. 38 .

Grant, F. S., 1954, A theory for the regional correction of potential field data, Geophysics, vol. 19, No. 1, pp. 23-45.

Grant, F. S., 1957, A problem in the analysis of geophysical data, Geophysics, vol. 22 , No. 2 , pp. 309-344.

Henderson, R. G., and Zietz, I., 1949, The upward continuation of anomalies in total magnetic fields, Geophysics, vol. 14, No. 4, pp. 517-534.

Hurwitz, L., Fabiano, E. B., and Peddie, N. W., 1974, A model of the geomagnetic field for 1970, Jour. Geophysics Research, vol. 79, No. 11, pp. 1716-1717.

Kane, M. F., 1973, The reference field in regional and local magnetic investigations, Internat. Assoc. Geomagnetism and Aeronomy, Bull. No. 34, p. 274.

Leaton, B. R., 1973, The International Geomagnetic Reference Field, Internat. Assoc. Geomagnetism and Aeronomy News, No. 12, p. 22.

Leaton, B. R., Malin, S. R. C., and Evans, M. J., 1965, An analytical representation of the estimated geomagnetic field and its secular change for epoch 1965.0, Jour. Geomagnetism and Geoelectricity, vol. 17, pp. 187-194.

Nettleton, L. L., 1954, Regionals, resíduals, and structures, Geophysics, vol. 19 , No. 1 , pp. 1-22.

Oldham, C. H. G., and Sutherland, D. B., 1955, Orthogonal polynomials; their use in estimating the regional effect, Geophysics, vol. 20, pp. 295-306. 
Peters, L. J., 1949, The direct approach to magnetic interpretation and its practical application, Geophysics, vol. 14, pp. 290-320.

Stern, D. P., and Bredekamp, J., 1974, Error enhancement in geomagnetic models derived from scalar data, Goddard Space Flight Center Technical Report, X-602-74-45.

Vajk, R., 1954, Notes on Fraser S. Grant's paper: "A theory for the regional correction of potential field data", Geophysics, vol. 19, No. 3, p. 569.

Zietz, I., and Zen, E., 1973, Northern Appalachians, Geotimes, vol. 18, No. 2, pp. 24-28.

Zmuda, A. J., 1971, World Magnetic Survey, Internat. Assoc. Geomagnetism and Aeronomy, Bull. No. 28. 